\title{
The Research Progress on Cocrystals of Flavonoids
}

\author{
Yingfan Xia, Renjie Xu, Chengjun Jiang* \\ School of Biological and Chemical Engineering, Zhejiang University of Science and Technology, Hangzhou, China \\ Email: *jcj312@zust.edu.cn
}

How to cite this paper: Xia, Y.F., Xu, R.J. and Jiang, C.J. (2022) The Research Progress on Cocrystals of Flavonoids. Open Access Library Journal, 9: e8320.

https://doi.org/10.4236/oalib.1108320

Received: December 23, 2021

Accepted: January 21, 2022

Published: January 24, 2022

Copyright $\odot 2022$ by author(s) and Open Access Library Inc.

This work is licensed under the Creative Commons Attribution International License (CC BY 4.0).

http://creativecommons.org/licenses/by/4.0/

\section{(c) (i) Open Access}

\begin{abstract}
Flavonoids are an important class of natural organic compounds that widely exist in nature and have rich medicinal value. Cocrystal technology is an effective method to improve the solubility of insoluble flavonoids. The cocrystal formers and the hydroxyl groups in the flavonoid compound form a new crystal structure through hydrogen bonding, and the original lattice packing and molecular arrangement have changed. On the premise of not changing the active ingredients of the drug, the solubility of the drug is improved, thereby improving the drug absorption and increasing the bioavailability. This article reviews the research progress of drug cocrystals of flavonoids, and provides a reference for the application of flavonoids in medicine.
\end{abstract}

\section{Subject Areas}

Chemical Engineering \& Technology

\section{Keywords}

Flavonoids, Cocrystal Technology, Traditional Chinese Medicine, Hydrogen Bond, Drug Absorption, Bioavailability

\section{Introduction}

\subsection{Flavonoids}

Flavonoids are an important class of natural organic compounds that widely exist in nature [1]. Due to their pharmacological functions and biological activities, such as anti-tumor, anti-inflammatory and antioxidation, flavonoids are the most widely used in the field of the food, medicine, and cosmetic [2]. Such compounds containing oxygen heterocycles are mostly found in higher plants and fern plants. Among them, the flavonoids contained in legumes, labiatae and 
asteraceae are abundant, and their core structure is 2-phenylchromone, the molecule usually contains multiple phenolic hydroxyl groups. Although the phenolic hydroxyl group is a hydrophilic group, the benzene ring in the molecule is a hydrophobic group. The presence of two benzene rings determines its low solubility in water and limits the application of flavonoids as oral preparations and injections [3].

\subsection{Cocrystal}

Cocrystal refers to a crystal formed by combining two or more molecules in the same crystal lattice through non-covalent bonds (hydrogen bond, $\pi-\pi$ stacking, van der Waals force, etc.) in a fixed stoichiometric ratio. It is a way of aggregation of multi-component substances in a solid state [4]. Pharmaceutical cocrystals specifically refer to the composition containing one or more active pharmaceutical ingredients (API), API and cocrystal formers (CCF) are solid at room temperature. The CCF must be a small molecule ligand, which is generally recognized as safe (GRAS) [4].

\subsection{Pharmaceutical Cocrystals Technology}

The pharmaceutical cocrystals technology is a widely accepted and clinically relevant technique that has prospered very well over the past decades to potentially modify the physicochemical properties of existing active pharmaceutic ingredients (APIs) without compromising their therapeutic benefits [5]. Due to the continuous efforts of pharmaceutical scientists and crystal engineers, cocrystal has now become a cutting-edge tool for adjusting the poor physical and chemical properties of API (such as solubility, permeability, bioavailability, improvement of poor mechanical properties, and taste masking) [5].

At present, the research hotspots of pharmaceutical cocrystal technology mainly focus on insoluble chemical drugs. Zhou et al. [6] reviewed the effects of cocrystals of insoluble active ingredients in various Chinese medicines on their physical and chemical properties and biological properties. There have been few reports on the cocrystal research of flavonoids. In this paper, the progress of cocrystal research and the effects of cocrystal on its physicochemical properties and bioavailability were summarized, so as to provide reference for the application of flavonoids in drugs.

\section{Cocrystal of Flavonoids}

Most of the molecular structures of flavonoids contain multiple phenolic hydroxyl groups, which can act as proton acceptors and proton donors, and can form various intermolecular hydrogen bonds with cocrystal formers (CCFs). The structures of flavonoids reported in the literature that can form cocrystals are shown in Figure 1. The flavonoids are luteolin, baicalein and chrysin; isoflavones are genistein and daidzein; dihydroflavonoids are naringenin and hesperetin; flavonols are quercetin, myricetin, fisetin, kaempferol; Dihydrochalcone 
is phloretin; Flavan-3-alcohols (Flavan-3-OLS) are (-)-catechins, (+)-catechin.

\subsection{Luteolin and Its Cocrystals}

Luteolin (Figure 2) was found in many kinds of vegetables and medicinal plants. It has a variety of pharmacological effects, including antioxidant, anti-inflammatory, anti-tumor, and nervous system protection. Due to the low solubility and low bioavailability, luteolin is difficult to prepare into medicines. However, preparing luteolin into drug cocrystals is beneficial to improve its bioavailability.

Zhang et al. [7] synthesized luteolin-4,4'-bipyridine drug cocrystal by solution evaporation method. Among them, luteolin and 4,4'-bipyridine were mixed in a ratio of $1: 3$ and dissolved in $7.0 \mathrm{~mL}$ of acetone solvent. After stirring for $3 \mathrm{~h}$ at $25^{\circ} \mathrm{C}$, it was volatilized at room temperature, and a yellowish-brown powder was obtained after 5 days. The crystal is the best cocrystal, and its physical and chemical

\section{Flavonoids}

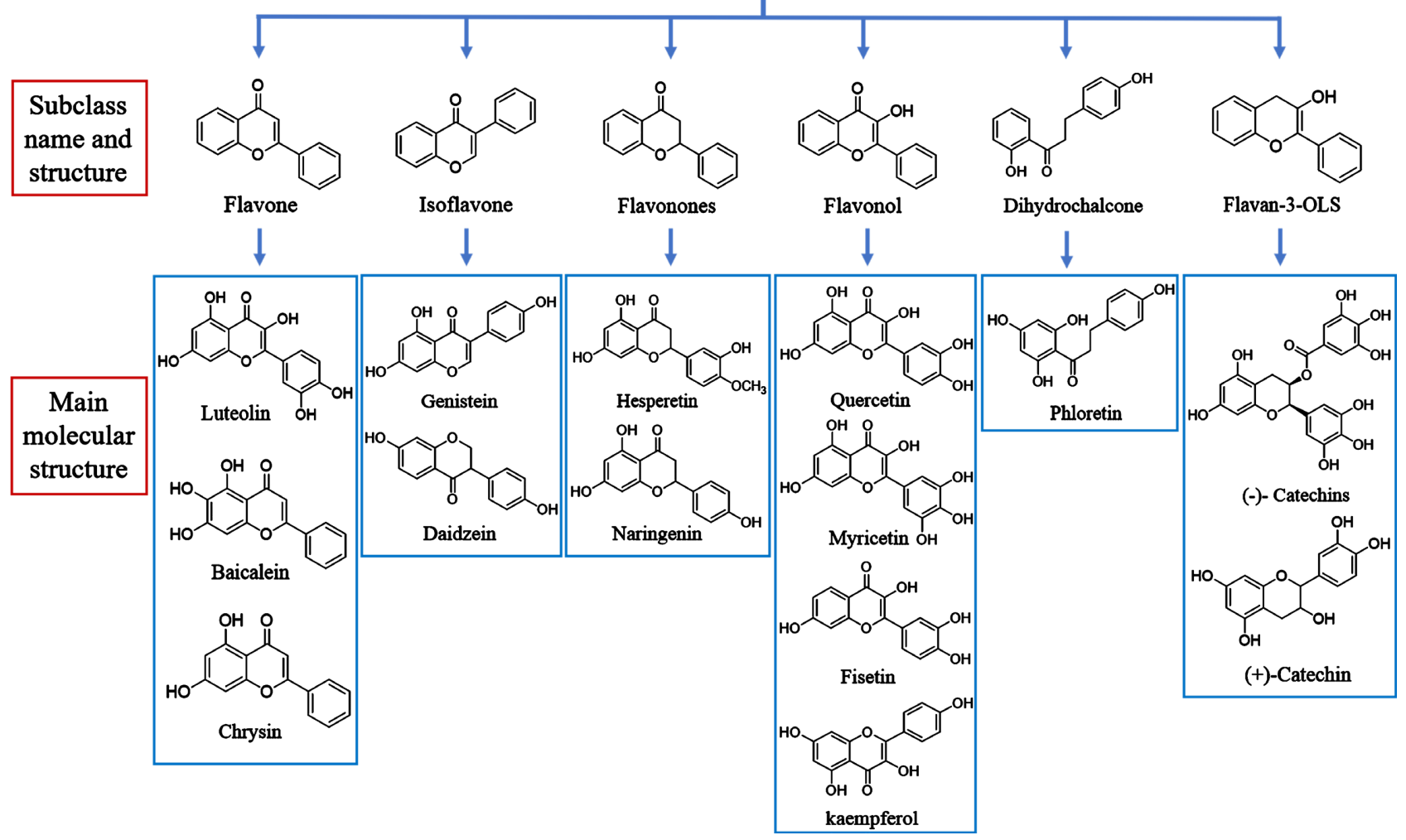

Figure 1. Host molecule structures of main flavonoids cocrystals.

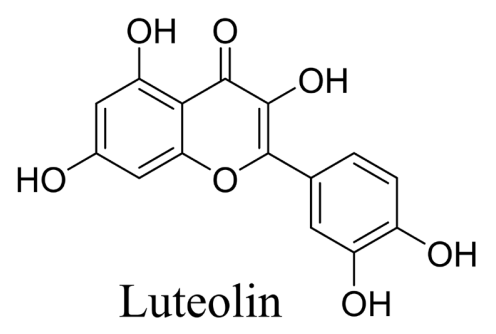

Figure 2. Luteolin molecular structure. 
properties need to be further studied.

He et al. [8] studied the zwitterionic cocrystal of D/L-proline and flavonoids in detail. Luteolin-D/L-proline cocrystal can be prepared either by slow solvent evaporation method or by suspension crystallization method. He et al. [8] gave the supramolecular structure of D/L-proline and flavonoids, as shown in Figure 3.

In the cocrystal structure, proline exhibits zwitterionic characteristics. He et al. [8] found that the ionic L-proline molecules are linked together to form a diline structure.

Luo et al. [9] successfully synthesized two new cocrystals of luteolin monohydrate-isoniazid and luteolin monohydrate-isocaffeine, using the liquid-assisted grinding method. The structure of the luteolin cocrystal formers were shown in Figure 4. The mixture of LUTmh and two coformers (ISN, CAF) in an equal molar ratio was manually ground with ethanol (a few drops) in a mortar for 30s. The two new cocrystals were carefully identified by X-ray diffraction, thermal and spectroscopic analysis; the temperature composition phase diagram of the two cocrystals was drawn by differential scanning calorimetry data. The maximum and minimum extreme values of all compounds that can be converted into hydrogen driving force on the surface of the molecular electrostatic potential are calculated and explained. Studies have found that the solubility of luteolin-isoniazid cocrystal $\left(112.3 \mu \mathrm{g} \cdot \mathrm{mL}^{-1}\right)$ is three times that of luteolin monohydrate. In the pharmacokinetic analysis, the $\mathrm{AUC}_{0-\infty}$ integral of cocrystal of luteolin-isoniazid cocrystals and luteolin-caffeine cocrystals were increased by 2.7 times and 1.4 times, respectively, compared with luteolin monohydrate.

\subsection{Baicalein and Its Cocrystals}

Baicalein (Figure 5) is one of the flavonoids with the highest content in scutellaria.<smiles>[R]c1cc(-c2oc3cc(O)cc(O)c3c(=O)c2[R])ccc1OCOC(=O)C(=O)OC</smiles>

Figure 3. Supramolecular heterosynthon between $\mathrm{D} / \mathrm{L}$-proline and flavonoids $(\mathrm{R}=\mathrm{H}$ or $\mathrm{OH})$.<smiles>NNC(=O)c1ccncc1</smiles>

Isoniazid<smiles>Cn1c(=O)c2c(ncn2C)n(C)c1=O</smiles>

caffeine

Figure 4. Structures of luteolin cocrystal formers. 
It has antipyretic, analgesic, anti-inflammatory, anti-tumor, antibacterial and antiviral, scavenging oxygen free radicals, anti-oxidation, protection of cardiovascular and cerebrovascular and neurons, liver protection, prevention or treatment of diabetes and its complications [10].

Zhu et al. [11] prepared a cocrystal of baicalein with isoniazid, pyrazinamide, caffeine, theophylline and proline. The structures of baicalein cocrystal coformers are displayed in Figure 6. The solubility of the cocrystal compound in $\mathrm{pH} 2.0$ hydrochloric acid buffer and $\mathrm{pH} 4.5$ phosphate buffer was determined, and the pharmacokinetic study was carried out.

The prepared baicalein and caffeine cocrystal has the best performance in solubility and pharmacokinetics. The solubility of the cocrystal in $\mathrm{pH} 2.0$ buffer is about 2.5 times that of baicalein, and about 1.5 times in $\mathrm{pH} 4.5$ buffer. Pharmacokinetic experiments in mice showed that the peak plasma concentration $\left(\mathrm{C}_{\max }\right)$ of the baicalein-caffeine cocrystal and the area under the plasma concentration-time curve $\left(\mathrm{AUC}_{0-24 \mathrm{~h}}\right)$ were 3.3 times and 4.1 times that of baicalein, respectively.

\subsection{Chrysin and Its Cocrystals}

Chrysin (Figure 7) is a kind of flavonoids with extensive pharmacological activity extracted from the bignoniaceae plant Orchidaceae. It has anti-inflammatory, antioxidant, anti-tumor, inhibition of aromatase activity, radiosensitization, prevention and treatment of cardiovascular and cerebrovascular diseases and<smiles>O=c1cc(-c2ccccc2)oc2cc(O)c(O)c(O)c12</smiles>

Figure 5. Baicalein molecular structure.<smiles>NNC(=O)c1ccncc1</smiles>
isoniazid<smiles>NC(=O)c1ccncc1</smiles>

pyrazinamide<smiles>Cn1c(=O)c2c(ncn2C)n(C)c1=O</smiles>

caffeine<smiles>Cn1c(=O)c2[nH]cnc2n(C)c1=O</smiles>

theophylline<smiles>O=C(O)C1CCCN1</smiles>

proline

Figure 6. Structures of baicalein cocrystal coformers.<smiles>O=c1cc(-c2ccccc2)oc2cc(O)cc(O)c12</smiles>

Figure 7. Baicalein molecular structure. 
other kind of pharmacological effects.

Chadha et al. [12] used the milling method to prepare cocrystals of chrysin-cytosine and chrysin-vitamin B1. And its solubility, pharmacokinetics, antioxidant activity, anti-hemolytic activity, etc. were studied. The structure of the chrysin cocrystal coformers is shown in the Figure 8. The concentration of chrysin in phosphate buffer at $\mathrm{pH} 6.8$ was $6.1 \mu \mathrm{g} \cdot \mathrm{mL}^{-1}$, while the solubility of cytosine and vitamin B1 cocrystal of chrysin was 13.7 and $24.8 \mu \mathrm{g} \cdot \mathrm{mL}^{-1}$, respectively. The relative biological activities of the two are 1.392 and 1.440. The oxidative activity and anti-hemolytic activity of the cocrystal compound are better than that of chrysin. After cocrystal formation of chrysin and proline, its solubility can be increased by $70 \%$.

\subsection{Genistein and Its Cocrystals}

Genistein (Figure 9) is a kind of isoflavones in legumes and one of the main phytoestrogens. It has a wide range of biological activities. In recent years, studies have found that genistein has a strong anti-cancer effect. The solubility of genistein-isonicotine and genistein-caffeine was made into cocrystals [13] [14], and the solubility of genistein-caffeine cocrystal in water-ethanol solution (1:1) was 1.5 times that of genistein. The cocrystal can remain stable within $24 \mathrm{~h}$ in the water-ethanol solution (1:1).

Based on the analysis of the relationship between the possible number of intermolecular $\mathrm{O}-\mathrm{H} \cdot \cdots \mathrm{N}$ hydrogen bonds and the stoichiometric ratio, Zhang et al. [15] prepared and characterized the $1: 1 \mathrm{C}_{15} \mathrm{H}_{10} \mathrm{O}_{5} \cdot \mathrm{C}_{10} \mathrm{H}_{8} \mathrm{~N}_{2}$ (Genistein-4,4'-bispyridine) cocrystal by solution evaporation method. It is proved that the stoichiometric ratio can be inferred by analyzing the number of possible intermolecular hydrogen bonds between flavonoids and amines. This strategy provides a simple way for the rational design of flavonoids and amine cocrystals. In addition, compared with pure genistein, cocrystal has advantages in solubility and antibacterial properties.<smiles>Nc1cc[nH]c(=O)n1</smiles>

Cytosine<smiles>CC1=C(CCO)SCC1=[N+](Cl)c1cnc(C)nc1N</smiles>

Vitamin B1<smiles>O=C(O)C1CCCN1</smiles>

Proline

Figure 8. Structures of chrysin cocrystal coformers.<smiles>O=c1c(-c2ccc(O)cc2)coc2cc(O)cc(O)c12</smiles>

Figure 9. Genistein molecular structure. 


\subsection{Daidzein and Its Cocrystals}

Soy isoflavones have the advantages of good tolerance and fewer adverse reactions. Daidzein (Figure 10) is one of the main active ingredients in soy isoflavones. Because of has a nucleus structure similar to estrogen, it has an estrogen-like effect [16]. At the same time, it has a significant antibacterial effect on Staphylococcus aureus and Escherichia coli.

Bhalla et al. [17] prepared daidzein cocrystals (daidzein-isonicotinamide DIS, daidzein-cytosine DCYT, daidzein-theobromine DTB) through a 1:1 ratio, and carried out screening experiments using solvent-assisted grinding methods. The obtained cocrystal was characterized by thermal and spectral properties. The data shows that intermolecular contacts are established in the cocrystal, and DAID all form hydrogen bonds with the complementary functional groups of CYT $(\mathrm{C}=\mathrm{O})$, TB $(\mathrm{OH})$ and ISO $(\mathrm{OH})$. Cocrystallization has been successful in improving the physical and chemical parameters of daidzein and optimizing bioavailability. In addition, the results of solubility studies are consistent with in vitro activities (anti-oxidation and anti-hemolysis studies) and in vivo experiments (anti-inflammatory activity). At the same time, compared with the pure components, the $\mathrm{C}_{\max }$ and AUC of the cocrystal increase sharply, thereby greatly improving the performance. The results show that cocrystallization can improve the solubility and bioavailability of daidzein.

\subsection{Hesperetin and Its Cocrystals}

Hesperetin (Figure 11) is the main medicinal ingredient in the fruit of the citrus plant of the Rutaceae family. It has the functions of invigorating the stomach, expectorating, antitussive, expelling wind, diuresis, antiviral, antibacterial, reversing and relieving stomach pain.

Chadha et al. [18] prepared a cocrystal of hesperetin with pyridine-2-carboxylic acid, nicotinamide and caffeine by solvent-assisted milling. The solubility was measured, and the DPPH free radical scavenging activity, anti-hemolytic activity,<smiles>O=C1c2ccc(O)cc2OCC1c1ccc(O)cc1</smiles>

\section{Daidzein}

Figure 10. Daidzein molecular structure.<smiles>COc1ccc(C2CC(=O)c3c(O)cc(O)cc3O2)cc1O</smiles>

Figure 11. Hesperetin molecular structure. 
pharmacokinetic test, and anti-inflammatory activity were studied. Table 1 shows the comparison of the properties of hesperetin and its cocrystals.

The $4 \mathrm{~h}$ dissolution profile data show that the solubility of hesperetin nicotinamide, hesperetin-caffeine, and hesperetin-pyridine-2-carboxylic acid in pure water is about 4 times that of hesperetin $\left(23.78 \mu \mathrm{g} \cdot \mathrm{mL}^{-1}\right)$. The antioxidant activity of hesperetin-caffeine, hesperetin-nicotinamide and hesperetin-pyridine-2-carboxylic acid can be increased by $50 \%, 30 \%$, and $20 \%$ respectively.

\subsection{Naringenin and Its Cocrystals}

Naringenin (Figure 12) is a glycoside of naringin, which is a dihydroflavonoid compound, which exists in rose family plants such as cherry blossoms, plums and other flower buds and citrus. Naringenin has a very wide range of pharmacological effects, manifested as hypolipidemic, anti-tumor, antibacterial, anti-inflammatory, antitussive and expectorant, antispasmodic and choleretic, scavenging free radicals, antioxidant, preventing and treating liver disease, inhibiting platelet coagulation, anti-atherosclerosis and other effects. However, naringenin is almost insoluble in water $\left(46 \pm 6 \mu \mathrm{g} \cdot \mathrm{mL}^{-1}, 298 \mathrm{~K}\right)$, its oral bioavailability is low (5.81\%) [19], and its clinical application is limited. Table 2 below provides the cocrystal reports of Naringenin with different cocrystal formers and their key findings.

\subsection{Quercetin and Its Cocrystals}

Quercetin (Figure 13) is a commonly used expectorant in TCM clinics. It has good expectorant and antitussive effects, as well as a certain anti-asthmatic effect. It also has the pharmacological activity of lowering blood pressure, improving capillary resistance, reducing capillary fragility, lowering blood lipids, dilating

Table 1. Comparison of the properties of hesperetin and its cocrystals.

\begin{tabular}{ccccccc}
\hline & $\begin{array}{c}\text { Solubility } \\
(\mu \mathrm{g} / \mathrm{mL})\end{array}$ & $\begin{array}{c}\text { Increased scavenging } \\
\text { rate of DPPH free } \\
\text { radical activity }(\%)\end{array}$ & $\begin{array}{c}\text { Increased } \\
\text { antihemolytic } \\
\text { activity }(\%)\end{array}$ & $\begin{array}{c}\mathrm{T}_{\max } \\
(\mathrm{min})\end{array}$ & $\begin{array}{c}\mathrm{C}_{\max } \\
(\mu \mathrm{g} / \mathrm{mL})\end{array}$ & $\begin{array}{c}\text { Relative } \\
\text { bioavail-ability }\end{array}$ \\
\hline Hesperetin & 23.78 & - & - & 180 & 0.47 & - \\
Hesperetin-Caffeine & 90.2 & 50 & 60 & 90 & 1.27 & 1.60 \\
Hesperetin-Nicotinamide & 94.02 & 30 & 40 & 90 & 1.15 & 1.57 \\
Hesperetin-pyridine-2-carboxylic acid & 68.54 & 20 & 30 & 120 & 0.63 & 1.36 \\
\hline
\end{tabular}<smiles>O=C1CC(c2ccc(O)cc2)Oc2cc(O)cc(O)c21</smiles>

Figure 12. Naringenin molecular structure. 
Table 2. Reported cocrystals of Naringenin with different cocrystal formers and their key findings.

\begin{tabular}{|c|c|c|c|}
\hline $\begin{array}{l}\text { Cocrystal Formers } \\
\text { (CCF) }\end{array}$ & Preparative Stratagy & Key Findings & References \\
\hline Isonicotinamide & $\begin{array}{l}\text { Suspension } \\
\text { Crystallization } \\
\text { (molar ratio } 1: 2 \text { ) }\end{array}$ & $\begin{array}{l}\text { - Obtained a naringenin-isonicotinamide cocrystal } \\
\text { - The dissolution behavior of the cocrystal has a significant } \\
\text { advantage over naringenin and its physical mixture. }\end{array}$ & {$[20]$} \\
\hline $\begin{array}{l}\text { Nicotinamide } \\
\text { Isonicotinamide } \\
\text { Caffeine } \\
\text { Betaine } \\
\text { L-proline }\end{array}$ & Solution Crystallization & $\begin{array}{l}\text { - the } \mathrm{C}_{\max } \text { of naringenin-L-proline and naringenin-betaine cocrystal } \\
\text { were } 2.00 \text { times and } 3.35 \text { times higher than that of pure naringenin } \\
\text { - the AUC of naringenin-L-proline and naringenin-betaine cocrystal } \\
\text { were } 2.39 \text { times and } 4.91 \text { times higher than that of pure naringenin }\end{array}$ & {$[21]$} \\
\hline $\begin{array}{l}\text { Piperazine salt } \\
\text { Flavone } \\
\text { 4-hydroxypyridine } \\
\text { Anthranilamide } \\
\text { 4,4'-bipyridine }\end{array}$ & $\begin{array}{l}\text { Solution Crystallization } \\
\text { (molar ratio 1:1) }\end{array}$ & $\begin{array}{l}\text { - The four neutral cocrystals maintain the } \mathrm{S}(6) \mathrm{O}-\mathrm{H} \cdots \mathrm{O}=\mathrm{C} \\
\text { intramolecular hydrogen bond seen in naringenin, and the } \\
\text { carbonyl oxygen atom is bifurcated. } \\
\text { - Solubility studies have shown that the formation of salt } \\
\text { significantly increases the solubility of naringenin. }\end{array}$ & [22] \\
\hline Carbamazepine & $\begin{array}{l}\text { Solvent Slow } \\
\text { Evaporation }\end{array}$ & $\begin{array}{l}\text { The results present that polyhydroxyl groups with the structural } \\
\text { features are effective to form typical intermolecular } \\
\text { amino } \cdots \text { hydroxyl interactions. } \\
\text { - CBZ-NRG cocrystal affects the in vitro/ vivo performance of CBZ } \\
\text { significantly (Table } 3 \text { ), demonstrating lower dissolution with } \\
\text { longer half-time life. }\end{array}$ & [23] \\
\hline Carbamazepine & $\begin{array}{l}\text { Drowning-out } \\
\text { Crystallization }\end{array}$ & $\begin{array}{l}\text { Naringenin }(\mathrm{N}) \text { and carbamazepine }(\mathrm{CBZ}) \text { cocrystallized at a } \\
\text { stoichiometric ratio of 1:1 via strong interactions between the } \\
\text { resorcinol groups of } \mathrm{N} \text { and the urea groups of CBZ. }\end{array}$ & [24] \\
\hline
\end{tabular}

Table 3. Pharmacokinetic parameters (mean \pm SD) for CBZ, CBZ-NRG cocrystal and CBZ-NRG physical mixture after oral administration $(20 \mathrm{mg} / \mathrm{kg}, \mathrm{n}=6)$.

\begin{tabular}{cccc}
\hline Parameters & CBZ & CBZ-NRG cocrystal & CBZ-NRG physical mixture \\
\hline $\mathrm{C}_{\max }(\mathrm{ng} / \mathrm{mL})$ & $5258.1 \pm 904.2$ & $491.3 \pm 97.6$ & $737.3 \pm 335.6$ \\
$\mathrm{~T}_{\max }(\mathrm{h})$ & $0.7 \pm 0.2$ & $8.5 \pm 1.0$ & $2.1 \pm 1.5$ \\
$\mathrm{t}_{1 / 2}(\mathrm{~h})$ & $1.6 \pm 0.1$ & $7.2 \pm 2.1$ & $10.2 \pm 6.1$ \\
$\mathrm{AUC}_{0-\infty}(\mathrm{ng} \cdot \mathrm{h} / \mathrm{mL})$ & $15,356.2 \pm 1756.4$ & $10,431.1 \pm 2014.3$ & $14,968.3 \pm 8135.7$ \\
\hline
\end{tabular}<smiles>O=c1c(O)c(-c2ccc(O)c(O)c2)oc2cc(O)cc(O)c12</smiles>

Figure 13. Quercetin molecular structure.

coronary arteries, and increasing coronary blood flow. However, the compound contains multiple phenolic hydroxyl groups and is weak in lipophilicity. At the same time, because the phenolic hydroxyl groups are easy to form hydrogen 
bonds between molecules, the crystal lattice energy is relatively high and the hydrophilicity is poor (the solubility of quercetin in water is $7 \mathrm{mg} \cdot \mathrm{L}^{-1}$ ), resulting in extremely low bioavailability. Table 4 provides the cocrystal reports of Quercetin with different cocrystal formers and their key findings.

\subsection{Myricetin and Its Cocrystals}

Myricetin (Figure 15) is the main chemical components of bayberry extract to exert pharmacological effects, and are also called bayberry flavonoids and myricetone. Myricetin has anti-tumor, neuroprotection, blood sugar lowering, antagonistic platelet activating factor, immune system and liver protection. Myricetin can form cocrystals with a variety of cocrystal formers (Figure 16). Myricetin has extremely low solubility in water $\left(<1.5 \mu \mathrm{g} \cdot \mathrm{mL}^{-1}, 25^{\circ} \mathrm{C}\right)$ [27], which greatly reduces its pharmacological effects. Xu et al. [28] added $800 \mathrm{mg}$ of myricetin and $488 \mathrm{mg}$ of caffeine (molar ratio of 1:1) to $40 \mathrm{~mL}$ of ethanol, sealed, stirred at $25^{\circ} \mathrm{C}$ for about $12 \mathrm{~h}$, filtered the resulting suspension, and the resulting product was dried in a vacuum drying oven at $25^{\circ} \mathrm{C}$ for $12 \mathrm{~h}$, the myricetin-caffeine cocrystals was obtained, and the dissolution rate of myricetin was increased by about 17 times compared with pure myricetin.

\subsection{Fisetin and Its Cocrystals}

Fisetin (Figure 17) is a flavonoid compound widely found in plants. It can exert anti-tumor effects by inducing tumor cell apoptosis, affecting tumor cell signal transduction pathways, inhibiting tumor cell proliferation, and inhibiting tumor cell migration and invasion.

Bhalla et al. [33] used mechanochemical grinding to cocrystallize glutaric acid

Table 4. Reported cocrystals of Quercetin with different cocrystal formers and their key findings.

\begin{tabular}{|c|c|c|c|}
\hline $\begin{array}{l}\text { Cocrystal } \\
\text { Formers (CCF) }\end{array}$ & $\begin{array}{l}\text { Preparative } \\
\text { Stratagy }\end{array}$ & Key Findings & References \\
\hline $\begin{array}{l}20 \text { kinds } \\
\text { (Figure 14) }\end{array}$ & $\begin{array}{l}\text { solvent-assisted } \\
\text { milling }\end{array}$ & $\begin{array}{l}\text { - The stability studies demonstrated that the cocrystals were more stable } \\
\text { towards water vapor than the pristine quercetin. } \\
\text { - The antioxidant activity of quercetin was improved through cocrystallization } \\
\text { with edaravone and kojic acid. } \\
\text { - The best inhibitory activity to pathophysiological proteases was observed for } \\
\text { the cocrystals of Qu with acetylcytosine, carnitine, and kojic acid. These } \\
\text { complexes were the most potent inhibitors of thrombin. } \\
\text { - About two times better cytotoxic activity to human cervical cancer cells } \\
\text { (HeLa) and human colon cancer cells (Caco-2) in comparison with } \\
\text { quercetin itself was observed for quercetin in complex with kojic acid. }\end{array}$ & {$[25]$} \\
\hline Nicotinamide & $\begin{array}{l}\text { Solvent } \\
\text { Evaporation }\end{array}$ & $\begin{array}{l}\text { - The hydrogen bond established between quercetin and nicotinamide in the } \\
\text { quercetin-nicotinamide cocrystal. } \\
\text { - The dissolution rate of quercetin-nicotinamide cocrystal was significantly } \\
\text { higher than that of quercetin cocrystal. } \\
\text { - The quercetin-nicotinamide cocrystal can significantly increase the oral } \\
\text { absorption of quercetin by nearly } 4 \text { times. }\end{array}$ & [26] \\
\hline
\end{tabular}


<smiles>CN1C(=O)NC(=O)C2C1=NCN2C</smiles><smiles>O=C(O)c1ccc(O)c(O)c1</smiles><smiles>O=C(O)c1cccc(O)c1</smiles><smiles>NC(=O)c1cc(O)c(O)c(O)c1</smiles>

Theobromine

3,4-Dihydroxybenzoic acid

3-hydroxybenzoic acid

3,4,5-Trihydroxybenzamide<smiles>N=C(N)n1cccn1</smiles>

Pyrazole-1-carboxamidine monohydrochloride<smiles>CC(=O)Nc1cc[nH]c(=O)n1</smiles><smiles>CN1CCN(C)C1=O</smiles><smiles>CC(O)C(N)=O</smiles><smiles>NC(N)=O</smiles>

Urea<smiles>O=C(O)c1cc(S(=O)(=O)O)ccc1O</smiles>

5-sulfosalicylic acid<smiles>NCC(CC(=O)O)c1ccc(Cl)cc1</smiles>

Baclofen<smiles>CN(C)N=Nc1nc[nH]c1C(N)=O</smiles>

Dacarbazine<smiles>O=C(O)c1cc(-c2ccc(F)cc2F)ccc1O</smiles>

Diflunisal<smiles>C[N+](C)(C)CC(O)CC(=O)O</smiles>

L-carnitine<smiles>O=c1[nH]cnc2[nH]ncc12</smiles>

Allopurinol<smiles>OCCN(CCO)c1nc(N2CCCCC2)c2nc(N(CCO)CCO)nc(N3CCCCC3)c2n1</smiles>

Dipyridamole<smiles>NC(=O)CN1CCCC1=O</smiles><smiles>NC(=O)c1ccccc1O</smiles>

Piracetam<smiles>CC1=NN(c2ccccc2)C(=O)C1</smiles>

Edaravone<smiles>O=c1cc(CO)occ1O</smiles>

Aspergillic acid

Figure 14. Structures of quercetin cocrystal coformers.<smiles></smiles>

Figure 15. Myricetin molecular structure. 
<smiles>NC(=O)CN1CCCC1=O</smiles><smiles>NC(=O)c1ccncc1</smiles>

Isonicotinamide<smiles>N#Cc1ccncc1</smiles>

4-cyanopyridine<smiles>NC(=O)c1cccnc1</smiles>

Nicotinamide<smiles>Cn1c(=O)c2c(ncn2C)n(C)c1=O</smiles>

Caffeine<smiles>O=C(O)C1CCCN1</smiles>

Proline<smiles>c1ccc(-c2ccccn2)nc1</smiles>

4,4'-Bipyridine

Figure 16. Structures of myricetin cocrystal formers.

Table 5. Reported cocrystals of Myricetin with different cocrystal formers and their key findings.

\begin{tabular}{|c|c|c|c|}
\hline $\begin{array}{l}\text { Cocrystal Formers } \\
(\mathrm{CCF})\end{array}$ & $\begin{array}{l}\text { Preparative } \\
\text { Strategy }\end{array}$ & Key Findings & References \\
\hline $\begin{array}{l}\text { Caffeine } \\
\text { Isonicotine } \\
\text { Nicotinamide } \\
\text { 4-cyanopyridine }\end{array}$ & $\begin{array}{l}\text { Solvent } \\
\text { Crystallization }\end{array}$ & $\begin{array}{l}\text { - Studies have shown that the solubility increases by } 3 \text { to } 80 \text { times after the } \\
\text { formation of the cocrystal, and the peak time is reduced to } 10 \text { to } 20 \text { minutes. }\end{array}$ & [29] \\
\hline Proline & $\begin{array}{l}\text { Solution } \\
\text { Crystallization }\end{array}$ & $\begin{array}{l}\text { - The highest solubility of myricetin-proline cocrystal in } 40 \text { minutes is } 7.69 \\
\text { times that of myricetin flavone and } 2.83 \text { times that of myricetin-proline } \\
\text { physical mixture. } \\
\text { - The blood concentration of myricetin in the cocrystal is about } 3.45 \text { times } \\
\text { higher than that of pure myricetin. }\end{array}$ & [30] \\
\hline 4,4'-bipyridine & $\begin{array}{l}\text { Solution } \\
\text { Evaporation }\end{array}$ & $\begin{array}{l}\text { - This work successfully demonstrates that the stoichiometric ratio could be } \\
\text { inferred by analysing the possible number of intermolecular hydrogen bonds } \\
\text { between flavonoids and amines. } \\
\text { - The results showed that the cocrystal compound has a broader antibacterial } \\
\text { activity than a single myricetin. }\end{array}$ & {$[15]$} \\
\hline $\begin{array}{l}\text { API: } \\
\text { Dihydromyricetin } \\
\text { CCF: } \\
\text { Caffeine; Urea }\end{array}$ & $\begin{array}{l}\text { Solution } \\
\text { Crystallization }\end{array}$ & $\begin{array}{l}\text { - This study demonstrates that the use of a highly soluble cocrystal along with } \\
\text { an appropriate crystallization inhibitor is a potentially effective formulation } \\
\text { strategy for improving oral bioavailability of poorly soluble BCS IV drugs. }\end{array}$ & [31] \\
\hline Berberine chloride & $\begin{array}{l}\text { Solution } \\
\text { Crystallization }\end{array}$ & $\begin{array}{l}\text { - The hydroxyl group of myricetin form } \mathrm{O}-\mathrm{H}_{\text {.... }} \mathrm{Cl}^{-} \text {with chloride anions, and } \\
\text { the intermolecular interactions dominate the formation of cocrystal. } \\
\text { - Cocrystals revealed low moisture adsorption up to } 95 \% \text { of relative humidity } \\
\text { and enhanced solubility in water. }\end{array}$ & [32] \\
\hline
\end{tabular}<smiles>O=c1c(O)c(-c2ccc(O)c(O)c2)oc2cc(O)ccc12</smiles>

Fisetin

Figure 17. Fisetin molecular structure. 
(GLU), malic acid (Mal) and theophylline (THY) with GRAS status and fisetin (F) to form three cocrystals FGLU and FMAL and FTHY. In terms of hydrogen bonding, all cocrystal formations are complementary to fisetin. The researchers used DSC, FT-IR, PXRD and solid-state NMR to analyze FGLU, FMAL and FTHY, and used PXRD patterns to analyze the crystal structure. The data shows that in each crystal structure, intermolecular hydrogen bond groups between the hydroxyl $(\mathrm{OH})$ and co-conformation carbonyl and phenol groups of fisetin can be observed. In the process of further evaluating its solubility, intrinsic dissolution rate and in vivo/ in vitro profile, it was found that the solubility and dissolution rate of the cocrystal in aqueous buffer showed that the solubility was about 1.8 - 3.0 times higher than that of the parental flavonoid molecule, thereby improving the pharmacokinetic parameters.

\subsection{Kaempferol and Its Cocrystal}

Kaempferol (Figure 18) is widely found in various fruits, vegetables and beverages. It has anti-cancer, anti-cancer, anti-inflammatory, anti-oxidant, anti-bacterial, anti-viral and other effects.

Su et al. [34] designed and synthesized a new cocrystal of kaempferol and 4,4'-bipyridine (KAE-BPY). 3'-OH neither participates in the formation of building units, nor does it play an important role in the 2D layer. Structural analysis shows that kaempferol molecules are alternately connected with 4,4'-bipyridine molecules, forming structural units through $7-\mathrm{OH}$ and 4'-OH hydrogen bonds. The structure of KAE.BPY is similar to that of QUE.BPY (quercetin and 4, 4'-bipyridine cocrystal). By analyzing the intermolecular interactions of building blocks and finding the correct structure of active pharmaceutical ingredients, new cocrystals can be designed and synthesized. In addition, the cocrystal of kaempferol and 4,4'-bipyridine has advantages over pure kaempferol in terms of hygroscopic stability.

\subsection{Phloretin and Its Cocrystals}

Phloretin (Figure 19) belongs to flavonoids and is a natural active substance. It is mostly distributed in the peel and root bark of juicy fruits such as apples and pears. A large number of studies at home and abroad have proved that phloretin has a wide range of pharmacological effects such as anti-inflammatory, anti-tumor, anti-oxidation, and promoting bone formation. However, phloretin's poor water<smiles>O=c1c(O)c(-c2ccc(O)cc2)oc2cc(O)cc(O)c12</smiles>

\section{kaempferol}

Figure 18. Kaempferol molecular structure. 
solubility, unstable chemical properties, and low absorption in the body severely restrict its clinical application [35].

In order to improve the dissolution performance of these compounds, Zhang et al. [36] chose the natural sweetener betaine (BTN) and flavonoids to form a cocrystal, and successfully conducted a cocrystallization test between BTN and phloretin. The crystal structure revealed and confirmed that the cocrystal has a typical supramolecular heterosynthesis of hydroxyl...carboxylate. Compared with pure flavonoids, the apparent solubility of the cocrystal is improved. These results indicate that BTN may be used as a potential symbiotic agent to form cocrystals with flavonoids to enhance performance.

\subsection{3. (-)-Catechins and Its Cocrystals}

(-)-Catechins (Figure 20) are widely used in the treatment of cancer, Alzheimer's disease, obesity, and diabetes.

Smith et al. [37] prepared (-)-catechin acid ester-isonicotinamide, (-)-catechin acid ester-isonicotinic acid, (-)-catechin acid ester-niacinamide, and (-)-catechin acid ester-nicotinic acid cocrystals, which were taken orally in rats, and the blood drug concentration in rats was measured within 8 hours. The research results show that the pharmacokinetic data of $(-)$-catechin ester cocrystal is better than single (-)-catechin ester, and the cocrystal can be used as a more effective therapeutic agent.<smiles>O=C(CCc1ccc(O)cc1)c1c(O)cc(O)cc1O</smiles>

\section{Phloretin}

Figure 19. Phloretin molecular structure.<smiles>O=C(O[C@H]1Cc2c(O)cc(O)cc2O[C@H]1c1cc(O)c(O)c(O)c1)c1cc(O)c(O)c(O)c1</smiles>

\section{(-)- Catechins}

Figure 20. (-)-Catechins molecular structure. 


\subsection{4. (+)-Catechins and its cocrystals}

$(+)$-Catechin (Figure 21) is widely distributed in the plant kingdom. It has the same two important functional components in tea as caffeine. It has multiple functions such as preventing cardiovascular diseases and cancer.

Spizzirri et al. [38] synthesized (+)-catechin and L- (+)-ascorbic acid, and the obtained cocrystal showed three times higher solubility than $(+)$-catechin, and its formation process was clearly clarifies passed FT-IR, DSC and PXRD. The antioxidant properties of the samples were evaluated by colorimetric analysis, which showed better antioxidant properties than ready-made lemon and peach teas.

\section{Summary and Outlooking}

During the development of innovative drugs, the poorly soluble drug candidates of BCS II and BCS IV accounted for nearly $90 \%$; among the drugs already on the market, the poorly soluble drugs accounted for less than $40 \%$. When solid active ingredients are finally on the market, solubility is an issue that cannot be circumvented. If the solubility is not good, it cannot be well absorbed. A large number of drug candidates were forced to stop development because they did not find a suitable solubilization method. Due to the high cost and hard-won of early candidate drugs, how to quickly and efficiently screen solubilization methods with milligram-level compounds, improve PK and shorten the development cycle, is increasing year by year.

Flavonoids have a wide range of pharmacological activities, but solubility problems limit their wide use in medicine. Using cocrystal technology, the introduction of new pharmaceutically acceptable cocrystal formers such as Caffeine, Niacin, Isonicotinamide, etc., without changing the structure of flavonoids, can effectively improve the physical and chemical properties of flavonoids, such as improving solubility, improved bioavailability, etc., further promote the development of insoluble active ingredients in the field of pharmacy.

However, there are still some problems. For example, the study of Myricetin cocrystal only compared the difference in antibacterial properties of cocrystals against Staphylococcus aureus and Escherichia coli, but the research of its anti-tumor, neuroprotective, and hypoglycemic efficacy was not carried out.<smiles>Oc1cc(O)c2c(c1)OC(c1ccc(O)c(O)c1)C(O)C2</smiles>

\section{$(+)$-Catechin}

Figure 21. (+)-Catechin molecular structure. 
The solubility of fisetin-isonicotinamide, fisetin-caffeine, and fisetin-nicotinamide is more than twice that of fisetin, but its main anti-tumor properties have not been further studied.

It is imminent to carry out research to improve the drug-readiness of drugs through cocrystals. It is of great significance. It is an effective and fast new way for the secondary development of flavonoids and the development of drugs with independent intellectual property rights. It will be the focus and hotspot of future research.

\section{Acknowledgements}

Authors sincerely acknowledge and express kind gratitude to all the authors of the publications and other contents used in the writing of this review paper entitled "The Research Progress on Cocrystals of Flavonoids."

\section{Conflicts of Interest}

The authors declare no conflicts of interest.

\section{References}

[1] Zhao, X.Y., Chen, J., Fang, J.G., et al. (2018) Study Progress on Antiviral Activities and Mechanisms of Flavonoids in Traditional Chinese Medicine and Natural Medicines. Herald of Medicine, 37, 410-415.

[2] Quan, C., Yao, H. and Hou, C. (2013) Certification and Uncertainty Evaluation of Flavonoids Certified Reference Materials. Agricultural Sciences, 4, 89-96. https://doi.org/10.4236/as.2013.49B016

[3] Lu, X. and Jiang, C.J. (2019) Research Progress on Cocrystal of Flavonoids. Herald of Medicine, 38, 921-926.

[4] Zhang, Z., Li, D., Luo, C., et al. (2019) Cocrystals of Natural Products: Improving the Dissolution Performance of Flavonoids Using Betaine. Crystal Growth \& Design, 19, 3851-3859. https://doi.org/10.1021/acs.cgd.9b00294

[5] Kumari, N. and Ghosh, A. (2020) Cocrystallization: Cutting Edge Tool for Physicochemical Modulation of Active Pharmaceutical Ingredients. Current Pharmaceutical Design, 26, 4858-4882. https://doi.org/10.2174/1381612826666200720114638

[6] Zhou, X.B., Wu, S.X., Sun, M.Y., et al. (2016) Research Progress on Co-Crystals of Insoluble Active Ingredients of Chinese Materia Medica. Chinese Herbal Medicines, 47, 336-343.

[7] Zhang, Y.N., Yin, H.M., Zhang, Y., et al. (2015) Synthesis and Characterization of Pharmaceutical Co-Crystal of Luteolin with 4,4'-Dipyridy. Journal of Northeast Agricultural University, 46, 72-78.

[8] He, H.Y., Huang, Y., Zhang, Q., et al. (2016) Zwitterionic Cocrystals of Flavonoids and Proline: Solid-State Characterization, Pharmaceutical Properties and Pharmacokinetic Performance. Crystal Growth \& Design, 16, 2348-2356. https://doi.org/10.1021/acs.cgd.6b00142

[9] Luo, Y., Chen, S., Zhou, J., et al. (2019) Luteolin Cocrystals: Characterization, Evaluation of Solubility, Oral Bioavailability and Theoretical Calculation. Journal of Drug Delivery Science and Technology, 50, 248-254. 
https://doi.org/10.1016/j.jddst.2019.02.004

[10] Xin, W.Y., Song, J.K., He, G.R., et al. (2013) Progress in Pharmacological Study and the Underlying Mechanism of Baicalein and Baicalin. Chinese Journal of New Drugs, 22, 647-659.

[11] Zhu, B., Zhang, Q., Wang, J.R., et al. (2017) Cocrystals of Baicalein with Higher Solubility and Enhanced Bioavailability. Crystal Growth \& Design, 17, 1893-1901. https://doi.org/10.1021/acs.cgd.6b01863

[12] Chadha, R., Bhalla, Y., Nandan, A., et al. (2017) Chrysin Cocrystals: Characterization and Evaluation. Journal of Pharmaceutical and Biomedical Analysis, 134, 361-371. https://doi.org/10.1016/j.jpba.2016.10.020

[13] Sowa, M., Ślepokura, K. and Matczak-Jon, E. (2013) A 1:2 Cocrystal of Genistein with Isonicotinamide: Crystal Structure and Hirshfeld Surface Analysis. Acta Crystallographica Section C-Structural Chemistry, 69, 1267-1272. https://doi.org/10.1107/S0108270113029545

[14] Sowa, M., Ślepokura, K. and Matczak-Jon, E. (2014) Solid-State Characterization and Solubility of a Genistein-Caffeine Cocrystal. Journal of Molecular Structure, 1076, 80-88. https://doi.org/10.1016/j.molstruc.2014.07.036

[15] Zhang, T.N., Yin, H.M., Zhang, Y., et al. (2017) Preparation of a 1:1 Cocrystal of Genistein with 4,4'-Bipyridine. Journal of Crystal Growth, 458, 103-109. https://doi.org/10.1016/j.jcrysgro.2016.10.084

[16] Gao, D.D., Zhang, L.L., Chen, J.L., et al. (2020) Effect of Daidzein on Differentiation of Human Osteoblast-Like MG-63 Cells and Its Molecular Mechanism. Medical \& Pharmaceutical Journal of Chinese People's Liberation Army, 32, 10-14.

[17] Bhalla, Y., Chadha, K., Chadha, R., et al. (2019) Daidzein Cocrystals: An Opportunity to Improve Its Biopharmaceutical Parameters. Heliyon, 5, e02669.

https://doi.org/10.1016/j.heliyon.2019.e02669

[18] Chadha, K., Karan, M., Bhalla, Y., et al. (2017) Cocrystals of Hesperitin: Structural, Pharmacokinetic, and Pharmacodynamic Evaluation. Crystal Growth \& Design, 17, 2386-2405. https://doi.org/10.1021/acs.cgd.6b01769

[19] Kanaze, F.I., Bounartzi, M.I., Georgarakis, M., et al. (2007) Pharmacokinetics of the Citrus Flavanone Aglycones Hesperetin and Naringenin after Single Oral Administration in Human Subjects. European Journal of Clinical Nutrition, 61, 472-477. https://doi.org/10.1038/sj.ejcn.1602543

[20] Liang, S.J., Zhou, S.Y., Yang, S.T., et al. (2017) Thermodynamic Studies of Naringenin-Isonicotinamide Cocrystals. Acta Pharmaceutica Sinica, 52, 625-633.

[21] Cui, W.X., He, Z.H., Zhang, Y.T., et al. (2019) Naringenin Cocrystals Prepared by Solution Crystallization Method for Improving Bioavailability and Anti-Hyperlipidemia Effects. AAPS PharmSciTech, 20, 115. https://doi.org/10.1208/s12249-019-1324-0

[22] Khandavilli, U.B.R., Skořepová, E., Sinha, A.S., et al. (2018) Cocrystals and a Salt of the Bioactive Flavonoid: Naringenin. Crystal Growth \& Design, 18, 4571-4577. https://doi.org/10.1021/acs.cgd.8b00557

[23] Zhou, F., Zhou, J., Zhang, H., et al. (2019) Structure Determination and in Vitro/ Vivo Study on Carbamazepinenaringenin (1:1) Cocrystal. Journal of Drug Delivery Science and Technology, 54, Article ID: 101244. https://doi.org/10.1016/j.jddst.2019.101244

[24] Lee, C.C., Cho, A.Y., Yoon, W., et al. (2019) Cocrystal Formation via Resorcinol-Urea Interactions: Naringenin and Carbamazepine. Crystal Growth \& Design, 19, 3807-3814. https://doi.org/10.1021/acs.cgd.9b00269 
[25] Veverka, M., Dubaj, T., Gallovič, J., et al. (2015) Cocrystals of Quercetin: Synthesis, Characterization, and Screening of Biological Activity. Monatshefte für Chemie, 146, 99-109. https://doi.org/10.1007/s00706-014-1314-6

[26] Wu, N., Zhang, Y., Ren, J., et al. (2020) Preparation of Quercetin-Nicotinamide Cocrystals and Their Evaluation under in Vivo and in Vitro Conditions. RSC Advances, 10, 21852-21859. https://doi.org/10.1039/D0RA03324C

[27] Yao, Y., Lin, G., Xie, Y., et al. (2014) Preformulation Studies of Myricetin: A Natural Antioxidant Flavonoid. Pharmazie, 69, 19-26.

[28] Xu, J.J., Wei, Y.F., Qian, S., et al. (2016) Preparation of Myricetin-Caffeine Cocrystal and Its Single Crystal Analysis. Journal of China Pharmaceutical University, 47, 324-328.

[29] Hong, C., Xie, Y., Yao, Y., et al. (2015) A Novel Strategy for Pharmaceutical Cocrystal Generation without Knowledge of Stoichiometric Ratio: Myricetin Cocrystals and a Ternary Phase Diagram. Pharmaceutical Research, 32, 47-60. https://doi.org/10.1007/s11095-014-1443-y

[30] Liu, M., Hong, C., Yao, Y., et al. (2016) Development of a Pharmaceutical Cocrystal with Solution Crystallization Technology: Preparation, Characterization, and Evaluation of Myricetin-Proline Cocrystals. European Journal of Pharmaceutics and Biopharmaceutics, 107, 151-159. https://doi.org/10.1016/j.ejpb.2016.07.008

[31] Wang, C., Tong, Q., Hou, X., et al. (2016) Enhancing Bioavailability of Dihydromyricetin through Inhibiting Precipitation of Soluble Cocrystals by a Crystallization Inhibitor. Crystal Growth \& Design, 16, 5030-5039. https://doi.org/10.1021/acs.cgd.6b00591

[32] Li, P., Ramaiah, T., Zhang, M., et al. (2019) Two Cocrystals of Berberine Chloride with Myricetin and Dihydromyricetin: Crystal Structures, Characterization and Anti-Tumor Activities. Crystal Growth \& Design, 20, 157-166. https://doi.org/10.1021/acs.cgd.9b00939

[33] Bhalla, Y., Chadha, R., Chadha, K., et al. (2019) Crystal Engineering of Fisetin: A Step towards Improved Biopharmaceutical Parameters. Journal of Food Science \& Technology, 4, 597-613. https://doi.org/10.25177/JFST.4.2.RA.461

[34] Su, X., Zhang, Y., Yin, H., et al. (2018) Preparation of a 1:1.5 Cocrystal of Kaempferol with 4,4'-Bipyridine Based on Analyzing Intermolecular Interaction of Building Units. Journal of Molecular Structure, 1177, 107-116. https://doi.org/10.1016/j.molstruc.2018.09.050

[35] He, X.L., Liu, Z.H., Wu, Y., et al. (2020) Preparation of Phloretin Inclusion Complex and Its Anti-Tumor Activity in Vitro. Journal of Hubei University of Chinese Medicine, 22, 48-51.

[36] Zhang, J.J., Qian, S. and Gao Y. (2019) The Theory and Application of Crystal Drug Development. Chemical Industry Press, Beijing, 162.

[37] Smith, A.J., Padmini, K., Arora, K.K., et al. (2013) Crystal Engineering of Green Tea Epigallocatechin-3-gallate (EGCg) Cocrystals and Pharmacokinetic Modulation in Rats. Molecular Pharmaceutics, 10, 2948-2961. https://doi.org/10.1021/mp4000794

[38] Spizzirri, U.G., Carullo, G., Cicco, L.D., et al. (2019) Synthesis and Characterization of a (+)-catechin and L-(+)-ascorbic Acid Cocrystal as a New Functional Ingredient for Tea Drinks. Heliyon, 5, e02291. https://doi.org/10.1016/j.heliyon.2019.e02291 